\title{
Prevalence of Diabetes Mellitus among Sub-Urban Pulation in Makassar, Indonesia
}

\author{
Adam Fabiola MS ${ }^{1}$, Adam John $\mathrm{MF}^{2}$, Seweng A ${ }^{3}$, Nang EE Khaing ${ }^{4}$, Tai ES ${ }^{5}$ \\ ${ }^{1,2}$ Division of Endocrinology and Metabolism Department of Internal Medicine, Faculty of Medicine, Hasanuddin \\ University Makassar Indonesia \\ ${ }^{3}$ Department of Biostatistics Faculty of Public Health Hasanuddin University, Makassar-Indonesia \\ ${ }^{4}$ Saw Swee Hock of Public Health, National University of Singapore \\ ${ }^{5}$ Department of Endocrinology, National University of Singapore
}

\begin{abstract}
Aims: In the last two decades, diabetes mellitus is increasing worldwide especially in the developing countries. Our early study in 1982 reported a prevalence of diabetes mellitus only 1.5\%. Cange of lifestyle will increase the incidence of diabetes mellitus. Aim of the study is to find out the impact of lifestyle changes on the prevalence of diabetes mellitus at the same area. Methods: The study was conducted at the same area, kecamatan Rappocini-Makassar, a medium socio-economic class, with a total adult population (> 16 years old) of 150,167 people. A questionnaire was prepared before the study. Those who had been treated for diabetes mellitus defined as known diabetic. Newly diabetic patient was diagnosed if fasting plasma glucose $\geq 126 \mathrm{mg} / \mathrm{dL}$. The population was classified according to ethnic grops, Makassar, Bugis, and Toraja. Results: During the study, 3502 subjects can be covered more females than males. In this study, 319 subjects fulfilled the criteria diabetes mellitus, a prevalence of 9.1\%, more males than females. There was a significant trend of prevalence with increasing age, high prevalence was found after the age of 50 years old. Between gender, the prevalence was significant higher in males. There was no significant different between ethnics Makassar, Bugis and Toraja, The same result was found among educational status, even though it was more frequent in those who were elementary school. Conclusions: Lifestyle changes increased the prevalence of diabetes mellitus at the same area.
\end{abstract}

Keyword: diabetes mellitus, prevalence, change of lifestyle

\section{Background}

Back to the year 1921, Prof Eliot P Joslin, an expert in diabetes, predict that in the coming three decades, the prevalence of diabetic patients will increase at least two times. Change of lifestyle, overeating and sedentary life, especially in the developing countries, will increase obesity and diabetes mellitus. According to World Health Organization, the diabetic population in year 2007 is around $6.0 \%$, and the next twenty years increased to $7.3 \%$, or from 250 million to 380 million, most of them among the developing countries. ${ }^{1}$

Population based studies of diabetes mellitus in Indonesia started in $1980 \mathrm{~s}$. In those studies, the prevalence was only between $1.5-2.0 \% .^{2,3,4}$ For nearly three decades (19822009) there is no new population based study, untill in 2009 a national survey was done. In this study which done in several urban area, covered 24.417 adult subjects Indonesia. ${ }^{5}$ The study reported a prevalence of diabetes mellitus 5,7\%, and impaired glucose test $10.2 \%$. Among the diabetic patients, $4.2 \%$ of them were newly diagnosed diabetes mellitus. From this study, we can conclude that lifestyle changes play an important role for the incresing of diabetes mellitus in Indonesia. Follow the national survey, other population based studies reported different prevalence. Yunir et $\mathrm{al}^{6}$ in 2009 , reported a prevalence of $14.24 \%$ in Depok-West Java. Suastika ${ }^{7}$ in 2010 reported only 5.9\%, but this study was done in rural as well as urban area.

Our first study was conducted in 1982 at kecamatan Rappocini, a sub-urban area with medium socio-economic class population in Makassar, The prevalence of diabetes mellitus at that time was only $1.5 \%{ }^{4}$ Nearly 20 years after the first screening, the population at the same area not only increased but also had different in lifestyles. The purpose of this study is to find out the impact of lifestyle changes on the prevalence of diabetes mellitus.

\section{Research Designs and Methods}

\section{Study Participants}

This study was a cross sectional study, as part of LIFEcourse study in CARdiovascular disease Epidemiology (LIFECARE) conducted between May 2009 to October 2011 (29 months). Makassar is the largest city of East Indonesia with a population of 1.200 .000 . The city consist of 10 kecamatan and the screening was done in kecamatan Rappocini, a sub-urban area in Makassar. This kecamatan has a total adult population of 150,627 subjects, and classified as a medium socio-economic class in Makassar. For the studied subjects, a proportional random sampling was done among adults age $>16$ years. Following the total subjects in this area and the last prevalence of diabetes mellitus was $1.5 \%$, we calculated that the total target for this study should be minimal 2259 subjects. Most of the population can be divided into three different ethnics, Bugis, Makassar and Toraja.

\section{Data Collection}

For this population based study, we used the WHO step wise in collecting data. A standard questionnaire was prepared before the study, and trained staffs filled the questionnaire. The first step, was the demographic data by interviewing the 


\section{International Journal of Science and Research (IJSR) \\ ISSN (Online): 2319-7064 \\ Index Copernicus Value (2013): 6.14 | Impact Factor (2014): 5.611}

studied subjects. The second step, physical examination data such as anthropometric measurement (weight, height and waist circumference) and blood pressure. Waist circumference was measured horizontally in the middle between the last arcus costae and anterior spina iliaca in the medial axillaris line (in centimeter unit). Blood pressure was measured three times in sitting position using a standard mercury sphygmomanometer. Average of the three measurement was defined as the blood pressure of the subjects. The third step was laboratory examination, this including fasting plasma glucose and lipid profiles i.e. total cholesterol, LDL cholesterol, HDL cholesterol, and triglycerides. All blood samples was taken after 12-hour fasting by a phlebotomist, and were examined in the Central Prodia Laboratory Makassar. Cholesterol and triglycerides used homogenous enzymatic colorimetric assay, while plasma glucose by enzymatic hexokinase.

\section{Definition}

For abnormal central obesity we followed the Asian criteria, male $\geq 90 \mathrm{~cm}$ and female $\geq 80 \mathrm{~cm}$. Since the blood samples was taken only after 12-hour fasting, the definition of newly diagnosed diabetes mellitus if fasting plasma glucose $\geq 126$ $\mathrm{mg} / \mathrm{dL}$. Those who has been treated for diabetes mellitus was categorized as known diabetes mellitus. For hypertension we followed the JNC $7^{8}$ while abnormal lipid values we used the NCEP ATP III criteria. ${ }^{9}$ Educational status was categorized into three clinical groups, elementary, high school and University.

Statistical analysis was conducted by using SPSS 22.0 with significant level of 0.05 . The risk factors comparison between diabetic and non diabetic were performed using Pearson Chi-Square test. The results were shown in tables and figures.

\section{Results}

\section{Prevalence}

During the study, 3502 subjects can be covered, more females than males, 2549 females $(72.8 \%)$ and 953 males (27.2\%). Among the 3502 subjects, 319 patients fulfilled the criteria of diabetes mellitus or a prevalence of $9.1 \%$, where 179 patients or $5.1 \%$ were newly diagnosed diabetes mellitus and 140 or $4.0 \%$ as known diabetes mellitus. Table 1 showed the prevalence of diabetes mellitus according to age groups, which significantly increased with increasing age $(p<0.001)$. High prevalence of diabetes mellitus was found after the age of 50 years old.

Table 1: Prevalence of diabetes mellitus according to age groups $(n=3502)$

\begin{tabular}{|c|c|c|c|c|}
\hline \multirow{2}{*}{ Age (year) } & \multirow{2}{*}{$\mathrm{n}$} & \multicolumn{2}{|c|}{$\mathrm{DM}(\mathrm{n}=319)$} & \multirow{2}{*}{$\mathrm{p}^{*}$} \\
\cline { 3 - 4 } & & $\mathrm{n}$ & $\%$ & \\
\hline$<30$ & 322 & 11 & 3,4 & \\
\hline $30-39$ & 658 & 21 & 3,2 & \\
\hline $40-49$ & 1017 & 84 & 8,3 & 0.000 \\
\hline $50-59$ & 985 & 132 & 13,4 & \\
\hline $60-69$ & 427 & 57 & 13,3 & \\
\hline$\geq 70$ & 93 & 14 & 15,1 & \\
\hline
\end{tabular}

*Pearson's Chi Square test
Table 2 show the prevalence of diabetes mellitus between males and females according to age groups. In both gender there was a significant increasing prevalence of diabetes mellitus according to trend of increasing age $(p=0.047$ for males and $\mathrm{p}=0.001$ for females).

Table 2: Prevalence of diabetes mellitus in males and females $(n=3502)$

\begin{tabular}{|c|c|c|c|c|c|c|}
\hline \multirow{3}{*}{ Age (year) } & \multirow{3}{*}{$n$} & \multicolumn{4}{|c|}{$D M(n=319)$} & \multirow{3}{*}{ * } \\
\hline & & \multicolumn{2}{|c|}{ Male $(n=102)$} & \multicolumn{2}{|c|}{ Female $(n=217)$} & \\
\hline & & $n$ & $\%$ & $n$ & $\%$ & \\
\hline$<30$ & 322 & 6 & 7,5 & 5 & 2,1 & \\
\hline 30-39 & 658 & 9 & 6,1 & 12 & 2,3 & 1) 0,047 \\
\hline $40-49$ & 1017 & 19 & 8,1 & 65 & 8,3 & \\
\hline $50-59$ & 985 & 37 & 13,5 & 95 & 13,4 & 2) 0,001 \\
\hline $60-69$ & 427 & 24 & 13,8 & 33 & 13 & \\
\hline$\geq 70$ & 93 & 7 & 16,7 & 7 & 13,7 & \\
\hline
\end{tabular}

*Pearson's Chi Square test

${ }^{1)}$ The $\mathrm{p}$ value of DM prevalence comparison between age group for male

${ }^{2)}$ The $\mathrm{p}$ value of DM prevalence comparison between age gorup for female

Table 3 show the difference of prevalence of diabetes mellitus between gender, educational status and ethnic groups. Among gender the prevalence of diabetes mellitus is significant higher in males $(p=0.045)$. But there is no statistical difference between educational status as well as ethnic groups. Even though the prevalence of diabetes mellitus is more frequent among those in the educational status of elementary school group.

Table 3: Prevalence of diabetes mellitus by sex, education level and ethnics $(n=3502)$

\begin{tabular}{|c|l|c|c|c|c|}
\hline \multicolumn{2}{|c|}{ Variable } & \multirow{2}{*}{$\mathrm{n}$} & \multicolumn{2}{c|}{$\mathrm{DM}(\mathrm{n}=319)$} & \multirow{2}{*}{$\mathrm{p}^{*}$} \\
\cline { 3 - 6 } Sex & Male & 953 & 102 & 10,7 & \multirow{2}{*}{0,045} \\
\cline { 2 - 5 } & Female & 2549 & 217 & 8,5 & \\
\hline Educational $^{1)}$ & Elementary & 894 & 94 & 10,5 & \\
\cline { 2 - 5 } & High School & 2052 & 183 & 8,9 & 0,163 \\
\cline { 2 - 5 } & University & 549 & 42 & 7,7 & \\
\hline \multirow{3}{*}{ Ethnics $^{2)}$} & Bugis & 1022 & 85 & 8,3 & \\
\cline { 2 - 5 } & Makassar & 1173 & 109 & 9,3 & 0,695 \\
\cline { 2 - 5 } & Toraja & 464 & 43 & 9,3 & \\
\hline
\end{tabular}

*Pearson's Chi Square test

1)) Excluded non responded for educational level

${ }^{2)}$ Excluded non responded for ethnics group

In this study, newly diagnosed diabetes mellitus was 179 patients and known diabetes mellitus140 patients. Looking to the difference of cardiovascular risk factors between these two groups, only high fasting blood glucose levels $(\mathrm{p}=0.010)$ and low HDL-cholesterol $(\mathrm{p}=0.046)$, was found significantly difference, higher among known diabetic patients (Table 4). 


\section{International Journal of Science and Research (IJSR) \\ ISSN (Online): 2319-7064}

Index Copernicus Value (2013): 6.14 | Impact Factor (2014): 5.611

Table 4: Cardiovascular risk factors in newly diagnosed and known diabetes mellitus $(\mathrm{n}=319)$

\begin{tabular}{|c|c|c|c|c|c|}
\hline \multirow{2}{*}{ Variables } & \multicolumn{4}{|c|}{ Diabetes mellitus } & \multirow{2}{*}{ p $^{*}$} \\
\cline { 2 - 5 } & New (n=179) & \multicolumn{2}{|c|}{ Known (n=140) } \\
\cline { 2 - 5 } & Average & SD & Average & SD & \\
\hline Age (years) & 51,8 & 10,9 & 52,7 & 9,9 & 0,461 \\
\hline Waist circ. (cm) & 85,4 & 8,4 & 84,4 & 8,7 & 0,327 \\
\hline Systolic BP mmHg) & 130,3 & 23,4 & 130 & 26,4 & 0,915 \\
\hline Diastolic BP (mmHg) & 83,4 & 14,2 & 83,2 & 13,9 & 0,931 \\
\hline LDL Chol.(mg/dl) & 163,7 & 63,3 & 162,8 & 62,3 & 0,902 \\
\hline HDL Chol. (mg/dl) & 49,4 & 10,5 & 51,9 & 11,3 & 0,046 \\
\hline TG (mg/dl) & 177,5 & 97,8 & 186,4 & 123,5 & 0,476 \\
\hline FPG (mg/dl) & 194,1 & 58,6 & 213,2 & 72,7 & 0,010 \\
\hline
\end{tabular}

*Independent $\mathrm{t}$ test

$\mathrm{BP}=$ blood pressure; $\mathrm{TG}=$ triglyceride $; \mathrm{FPG}=$ fasting plasma glucose

$\mathrm{SD}=$ Standar Deviation

\section{Discussion}

The prevalence of diabetes mellitus depends on several factors i.e socio-economic class, age of the studied subjects, ethnic, and the criteria used for the screening. City of Makassar is the largest city in Eastern part of Indonesia, with a population of 1.2 million people, consisted of 10 kecamatan (districs). Kecamatan Rappocini, where the study was conducted, is a medium socio-economic class population, most of them are government employee. The prevalence of diabetes in this area was $9.1 \%$, lower than that reported by Yunir et al in Depok West Jawa, 14.2\%. ${ }^{6}$ This difference is not only due to different in socio-economic class population, but also the criteria used for diagnosis of diabetes mellitus. In our study the diagnosis of diabetes mellitus was only the fasting plasma glucose, while Yunir et al. ${ }^{6}$ besides fasting plasma glucose also included oral glucose tolerance test. According to the literature, using oral glucose tolerance test will detect more newly diagnosed diabetes mellitus, about $30.0 \%$ compared to only the fasting plasma glucose. ${ }^{10,11}$

Screening for diabetes mellitus is needed to detect the unknown diabetes melltius. Several studies reported that about $50.0 \%$ or even more of the population screening may detect newly diabetes mellitus more compared to known diabetes mellitus, especially in developing countries. ${ }^{5,12,13}$ In this study the newly diagnosed diabetes mellitus was higher compared to kown diabetes mellitus, $5.1 \%$ and $4.0 \%$ subsequently. This result is comparable to other studies ${ }_{5,13,14}$ Age play an important role in most studies of diabetic prevalence. The prevalence of diabetes mellitus increased with inceasing age. Most studies in Asian countries reported increased prevalence with increasing age ${ }^{5,13,14,15}$ This study, we found that the prevalence of diabetes mellitus also increased with increasing age, which more common after the age of 50 years old.

Most studies reported more diabetic patients in urban area than rural, ${ }^{6,13,16}$ Since our study was conducted in an urban area, the prevalence of diabetes mellitus was high, this result was the same as reported by several studies in Asian countries. ${ }^{6,14}$ In this study, there was no difference of diabetic prevalence between the three ethnic groups, Bugis, Makassar and Toraja. This might be due to the same lifestyle at that area, not by ethnic difference. Educational status is a good indicator of socio-economic status, and may play a role for the incidence of diabetes mellitus. Some studies report that those with lower educational status was inversely associated with diabetes prevalence. ${ }^{16,17,19}$ In this study, there was no significant difference between the educational status, even though the prevalence of diabetes mellitus was higher among those with lower educational status (elementary school). One possibility is that in this study more females than males, where most of the females were housewives.

Our study has several limitations. Firts, in this study the diagnosis of diabetes mellitus only by fasting plasma glucose, adding oral glucose tolerance test to define diabetes mellitus may find the exact prevalence of diabetes mellitus in this population. Beside diabetes mellitus, oral glucose tolerance test is also important to detect subjects with impaired glucose tolerance, as we know this prediabetes state has the same risk for cardiovascular event as diabetes mellitus Second, it was difficultt to ask the dietary intake since during the collecting data some of them were from the same family. As we know that dietary intake is an important risk factor for the incidence diabetes mellitus.

In summary, the prevalence of diabetes mellitus among urban medium socio-economic population was similar to other studies in Asian countries. There was not significant difference in ethnic groups as well as educational status.

\section{References}

[1] Intrenational Diabetes Federation. Diabetes Atlas, 3rd ed. 2006.

[2] Soetardjo, Moeljanto R. Diabetes Melitus di Kelurahan Pekajangan - Pekalongan. Naskah Lengkap KOPAPDI V. Semarang 1981; 99-105.

[3] Waspadji S, Ranakusuma AB, Sujono S, Supartondo, Sukaton U. Diabetes mellitus in an urban population in Jakarta. Acta medica Indonesian XIV: 123-130, 1983.

[4] Adam JMF. Survey diabetes mellitus pada sekelompok penduduk di Ujung Pandang. Penelitian Universitas Hasanuddin Ujung Pandang, 1982.

[5] Mihardja L, Delima, Siswoyo H, Ghani L, Soegondo S. Prevalence and Determinants of Diabetes Mellitus and Impaired Glucose Tolerance in Indonesia (A Part of Basic Health Research/Riskesdas). Acta Med Indones - Indones J Intern Med 2009; 41: 169 - 174.

[6] EM Yunir, Waspadji S, Rahajeng E. The Pre-diabetic Epidemiological Study in Depok, West Java. Acta Med Indonesiana, J Intern Med 2009: 41: 181 - 185

[7] Suastika K, Dwipayana P, Saraswati IMR, Gotera W, Budhiarta AAG, Sutanegara IND, et al. An epidemiological study on obesty, glucose intolerance and metabolic syndrome in population of Bali, Indonesia. Diabetes.2010, 59 (Suppl 1): A608.

[8] JNC 7 Express. The Seventh Report of the Joint National Committee on Prevention, Detection, Evaluation, and Treatment of High Blood Pressure. National Institutes of Health National Heart, Lung, and Blood Institute. U.S. Department Of Health and Human Se Rvices. NIH Publication No. 03-5233 December 2003. 


\section{International Journal of Science and Research (IJSR) \\ ISSN (Online): 2319-7064}

Index Copernicus Value (2013): 6.14 | Impact Factor (2014): 5.611

[9] Executive Summary of the Third Report of the National Cholesterol Education Program (NCEP) Expert Panel on Detection, Evaluation, and Treatment of High Blood Cholesterol in Adults (Adult Treatment Panel III). JAMA 2001; 285: 2486-2497.

[10] Age- and sex-specific prevalence of diabetes and impaired glucose regulation in 13 European cohorts: DECODE Study Group. Diabetes Care. 2003 Jan; 26(1):61-9.

[11] Cowie CC, Rust KF, Ford ES, Eberhardt MS, ByrdHolt DD, Li C, Williams DE, Gregg EW, Bainbridge KE, Saydah SH, Geiss LS. Full accounting of diabetes and Pre-diabetes in the US population in 1988-1994 and 2005-2006. Diabetes Care 2009; 32: 287-294.

[12] Mohan V, Deepa R, Deepa M, Somannavar S, Datta M. A simplified Indian diabetes risk score for screening for undiagnosed diabetic subjects. JAPI. 2005; 53: 759-63.

[13] Aekplakorn W, Chariyalertsak S, Kessomboon P, Sangthong R. Prevalence and Management of Diabetes and Metaboloc Risk Factors in Thai Adults. Diabetes Care 2011;34:1980-5.

[14] Tan CE, Emmanuel SC, Tan BY, Jacob E. Prevalence of diabetes and ethnic differences in cardiovascular risk Factors. The 1992 Singapore National Healthy Survey. Diabetes Care 1999; 22: 241 - 247.

[15] KIM SM, LEE JS, LEE J, NA JK, HAN JH, YOON DK, BAIK SH, CHOI DS, CHOI KM. Prevalence of Diabetes and Impaired Fasting Glucose in Korea. Korean National Health and Nutrition Survey 2001. Diabetes Care 29:226-231, 2006.

[16] Yang W, Lu J, Weng J, Jia W, Ji L. Prevalence of Diabetes among Men and Women in China. N Engl $\mathrm{J}$ Med 2010;362:1090-101.

[17] Borrell LN, Dallo FJ, and White K. Education and Diabetes in a Racially and Ethnically Diverse Population. Am J Public Health. 2006; 96:1637-1642.

[18] Seeman T, Merkin SS, Crimmins E, Koretz B, Charette S, Karlamangla A. Education, Income and Ethnic Differences in Cumulative Biological Risk Profiles in a National Sample of US Adults: NHANES III (1988-1994). Soc Sci Med. 2008; 66 (1): 72-87.

[19] Ko GTC, Chan JCN, Yeung VTF, Chow CC, Tsang LWW, Cockram CS. A low socio-economic status is an additional risk factor for glucose intolerance in high risk Hong Kong Chinese. European Journal of Epidemiology 2001; 17: 289-295. 